\title{
FOCALIZACIÓN, DISTANCIA Y TRATAMIENTO TEMPORAL. ESTUDIO DE LA IMPLICACIÓN SUBJETIVA EN EL DISCURSO FÍLMICO A TRAVÉS DEL ANÁLISIS NARRATOLÓGICO
}

\author{
FOCALIZATION, DISTANCE AND TEMPORARY TREATMENT. \\ STUDY OF THE SUBJECTIVE IMPLICATION IN THE DISCOURSE \\ THROUGH THE NARRATOLOGICAL ANALYSIS
}

\section{Fernando REDONDO NEIRA}

Universidad de Santiago de Compostela

fernando.redondo@usc.es

\begin{abstract}
Resumen: Todo relato cinematográfico articula una determinada manera de dar a ver y de dar a conocer. Entre los niveles discursivos del mostrar y del narrar que todo filme construye y comunica existe una amplia graduación de implicación subjetiva que focaliza el material narrativo y lo hace llegar al espectador. Este artículo se propone el análisis narratológico de tres filmes de muy distinta naturaleza discursiva. Se trata de otros tantos ejemplos a través de los cuales averiguar cómo el dispositivo enunciador ordena el relato entre la (íntima) proximidad, la (íntima) indiferencia y el saber precario.
\end{abstract}

Palabras clave: Mostrar. Narrar. Saber. Proximidad. Focalización

Abstract: Every cinematographic story constructs a certain way of leading to see and leading to know. Among the discursive levels of showing and 
telling that every film constructs and communicates, there is a wide range of subjective implication that focuses the narrative material and extend it to spectator. This article proposes the narratological analysis of three films of very different discursive nature. These are some examples through which to find out how the enunciating device orders the story between (intimate) proximity, (intimate) indifference and the precarious knowledge.

Key Words: Show. Narrate. Know. Proximity. Focalization.

\section{INTRODUCCIÓN}

Tres filmes surgidos en los años de la crisis, a la cual, de un modo $\mathrm{u}$ otro, remiten, y de la cual emergen en la forma de propuestas animadas por una cierta intención rupturista en lo estético, lo narrativo e, incluso, lo industrial, presentan, desde lo específico de cada caso, un rasgo común que los singulariza y vincula: la mobilización de un elocuente dispositivo enunciativo que organiza la materia narrativa en todo cuanto se refiere al hacer ver, el hacer saber y el hacer creer. Recurren para ello a aquellos mecanismos de focalización que reclaman, a su vez, la asunción de un determinado posicionamiento del espectador respecto de lo mostrado y de lo narrado. En este sentido, el análisis narratológico que aquí proponemos llevar a cabo se asentará, como no podía ser de otra forma, sobre la focalización en tanto que elemento estructurador inscrito en el modo narrativo, tal y como viene establecido desde Gerard Genette, que, como es notorio, viene demostrando su aplicabilidad a los estudios fílmicos, y que, le permitirá proponer esa distinción primordial entre el agente que narra los hechos y aquel otro desde cuya perspectiva los hechos son narrados (Genette, 1989: 244).

Sobre cómo se articula una cierta manifestación de la enunciación enunciada, analizaremos aquí tres títulos: Carmina o revienta (Paco León, 2012), El muerto y ser feliz (Javier Rebollo, 2012) y El futuro (Luis López Carrasco, 2013), que representan otros tantos procedimientos de articulación narrativa en los que, de un modo gradual de uno a otro título, aquella focalización se resuelve según diferentes modos de intervención de un enunciador (o megaenunciador), y que, según los casos, delega sus funciones en un narrador, que puede tratarse de un personaje-narrador, 
o bien en una una voz over no integrada en el universo de la ficción. Llevaremos a cabo, por tanto, y siguiendo lo indicado por Lozano, PeñaMarín y Abril, un análisis de la enunciación atendiendo, en lo fundamental, a aquellos marcadores textuales que advierten sobre la actitud del sujeto respecto a lo enunciado y sobre si allí se manifiestan sus opiniones o puntos de vista (Lozano, Peña-Marín y Abril,1998: 93). En esta línea, y sobre la actuación del sujeto de la enunciación, interesa para nuestro objetivo lo afirmado por Casetti, para quien aquél es dado a conocer por indicios o emergencias internas al filme y se constituye en el eje sobre el que giran las imágenes y los sonidos (Casetti, 1989: 43). En definitiva, procederemos a la evaluación de tres filmes que presentan, en su diversidad, otros tantos modos de inscribir las huellas de su propia enunciación, que deriva, además, en la asunción de un determinado modelo de relación con el espectador, lo que, de nuevo recurriendo a Casetti, supone la indagación acerca del "hacerse y el darse del filme" (1989: 58). Y en relación con la figura del espectador, precisamente, consideramos pertinente para nuestro propósito el concepto que de él maneja David Bordwell: "Entidad hipotética que realiza las operaciones relevantes para construir una historia partiendo de la representación del filme" (1996: 30). Según este autor, debe considerarse al espectador en un marco teórico general que atienda a aspectos perceptuales y cognitivos de la visión del filme. El ver y el saber, por tanto, que son tambión los dos ejes sobre los que se articula buena parte de nuestro análisis, de ahí que interese complementar nuestra propuesta metodológica con la aportación de Bordwell.

\section{MOSTRAR, VER Y SABER. ELEMENTOS DEL ENTRA- MADO NARRATIVO}

La compleja casuística que ha venido siendo elaborada en torno a la instancia narradora del cine da cuenta de la riqueza de registros, de los múltiples procedimientos posibles para canalizar el relato, para filtrarlo desde una determinada instancia discursiva, para, en definitiva, focalizar el mostrar y el saber.

Una primera toma de contacto con dicha complejidad conduce al concepto de punto de vista, concepto de amplio alcance semántico y, por tanto, de dudosa operatividad analítica por cuanto que lo mismo podría emplearse con el muy restrictivo significado de lo que comúnmente se 
conoce como plano subjetivo como con aquel otro que, de un modo general, alude a un determinado posicionamiento, o perspectiva, que se fijara ante los hechos narrados. De este modo, como tal toma de posición, bien podría tratarse, por un lado, de un concreto emplazamiento físico, un lugar de observación, como, por otro, de una más abstracta ubicación mental ante los acontecimientos objeto del relato, lo que incluiría, por ejemplo, una actitud o una postura ética. A este respecto, Casetti diferencia punto de vista de la imagen (que cambia con el cambio de encuadre) de punto de vista del filme (que opera globalmente, asumiendo las diversas propuestas), para finalmente entender dicho concepto como la "mirada total del film, sus medidas y sus perspectivas" (Casetti, 2003: 234). Hay que hacer notar, además, que Casetti asume la complejidad intrínseca de este concepto cuando, tras recoger y desarrollar una diferenciación previa de Chatman (1990: 163), le otorga una triple significación: una literal (a través de los ojos de alguien), una figurada (en la mente de alguien) y una metafórica (según la ideología o el provecho de alguien) (Casetti, 2003: 236). Añadamos, en relación con las dificultades que ofrece esta terminología, que Bal indica que "punto de vista" o "perspectiva narrativa" no discrimina entre los que ven y los que hablan, que se hace necesario distinguir, entonces, entre ambos agentes para describir adecuadamente la técnica de un texto (Bal, 1985: 108). Por eso afirma preferir el término focalización, referido a las relaciones entre los elementos presentados y la concepción a través de la cual se presentan; término, añade, de apariencia técnica y que se deriva de la fotografía y el cine, lo que, por supuesto, lo hace especialmente idóneo a nuestro objeto de estudio.

Sin la pretensión de resultar exhaustivos, pero sí de ir a lo que necesariamente hay que mencionar dado el lugar central que ocupa en todo cuanto aquí vamos a estudiar, habría que matizar que el concepto de focalización se define, en primer lugar, por una relación de saber entre el narrador y sus personajes, como se ocupan de destacar André Gaudreault y François Jost (1995: 139), siguiendo el camino abierto por Genette. En el caso del cine, como es notorio, se hizo necesario ir un paso más allá, como así hará Jost al diferenciar entre focalización, definible de un modo estricto como aquello que un personaje sabe, y ocularización, que establece la relación entre lo que la cámara muestra y lo que un personaje ve (1987: 106). Como también cabe recordar, en relación, asimismo, con el imprescindible concepto de focalización, la triple categorización 
que plantean Gaudreault y Jost, quienes de nuevo apoyan su propuesta en lo establecido por Genette: el relato no focalizado o focalización cero, por la cual se accede a un volumen de información superior a aquel del que disponen los personajes; el relato de focalización interna, que puede presentarse como fija, variable o múltiple, y que bien podrá aplicarse al caso de Carmina o revienta; el relato en focalización externa, considerable como relato behaviorista, que no permite conocer los pensamientos o sentimientos de los personajes, y cuya toma en consideración será especialmente útil para el análisis de El futuro (Gaudreault, Jost, 1995: 139). De especial relevancia para nuestro análisis será, en relación con lo expuesto hasta aquí, el acceso a la conciencia de un personaje a través de una determinada articulación del dispositivo enunciativo, tal como ha señalado Seymour Chatman (1990: 169), quien destaca esta función de filtro en lo que supone de canalización de la información narrativa a través de la psicología y las emociones de un personaje.

Considerando la ya citada complejidad que conlleva el entramado narrativo de todo discurso fílmico, conviene destacar ahora la figura del narrador cinemático, que debemos contemplar en los términos propuestos por Gómez Tarín: "Los diversos narradores se estructuran de acuerdo con dos elementos esenciales: su saber y la adopción de un punto de vista. Parámetros que son relacionales y sólo pueden entenderse a través de la intervención de la cámara como ente productor/receptor de la imagen" (2011:63). En tanto que instancia textual puede acogerse a alguna de las siguientes formulaciones, que serán las que apliquemos a nuestro análisis. En primer lugar, el personaje-narrador, o narrador intradiegético para Genette, que actúa como narrador desde el interior de la ficción. A su vez, puede tratarse de un narrador homodiegético, si se trata de un personaje integrado en la historia que él mismo relata, o bien de un narrador heterodiegético, si no aparece en la historia que relata. En cuanto al narrador extradiegético, presenta una mayor ambigüedad conceptual en relación con el personajenarrador. De él han dicho distintos especialistas que constituye un narrador impersonal, externo a los sucesos que narra, no identificable con un ser personal y desprovisto de cualquier rasgo antropomórfico. Stam, Burgoyne y Fitterman-Lewis, por ejemplo, han destacado que no se manifiesta a través del discurso verbal, sino por medio de todo un conjunto de códigos cinemáticos (1999: 120), para concluir que se presenta como aquella actividad discursiva o narrativa primaria que fluye del mismo medio que 
el cine (1999: 127). Finalmente, el narrador en voz over ocuparía esa otra zona de ambigüedad específica del cine, lugar incierto, flotante y, en todo caso, separado de la diégesis; lugar de la omnisciencia y del dominio sobre el relato y los personajes que lo habitan. Nos encontramos aquí con otra categoría problemática, pues en el sistema de Genette podrían adoptar la denominación de narradores heterodiegéticos, siendo los narradores over en tercera persona para Kosloff (1988: 82). Se trataría en todo caso, si adoptamos una terminología inclusiva, de narradores heterodiegéticos en voz over que asumen una posición de autoridad (de omnisciencia), que se manifiestan exclusivamente a través de un registro verbal; en definitiva, un narrador marco (otra terminología propuesta por Kosloff) no visualizado, carente de cuerpo y que ocupa el citado lugar flotante.

A partir de cualquiera de las anteriores modalidades de narrador, comparezcan o no a través de una voz o de un sujeto-personaje inscrito en la ficción, será posible realizar un análisis en torno al eje en el que se alinean el mostrar, el narrar, el experimentar, el saber o el sentir. Con ello se relaciona, sin duda, aquella distinción, no por elemental igualmente decisiva, entre mostración y narración, debida, en primer lugar, a Gaudreault (Gaudreault, Jost, 1995: 69), o esta otra relevante afirmación de Chatman, recogida por Stam, Burgoyne y Fitterman-Lewis: "Las películas son siempre presentadas, mayormente y a veces exclusivamente mostradas, pero en ocasiones son también parcialmente contadas por un narrador o narradores" (1999: 137).

En otro orden de cosas, y como es sabido, toda estructura narrativa se construye también, necesariamente, desde la dimensión temporal. Genette ha destacado que resulta casi imposible no situar la historia en el tiempo en relación con mi acto narrativo y añade que parece evidente que la narración no puede ser si no posterior a lo que cuenta (Genette, 1989: 274). De cara al estudio de cómo los filmes objeto de análisis crean y comunican sus significados, es preciso, por tanto, dirigir nuestra atención hacia el tratamiento temporal del relato, para lo cual nos acogemos a un punto de partida esencial que ya fue establecido por Paul Ricoeur en los siguientos términos:

El tiempo se hace tiempo humano en la medida en que se articula de un modo narrativo [...] La narración alcanza su plena significación cuando se convierte en una condición 
de la existencia temporal (1988: 117).

La intrínseca dimension temporal del relato comporta, además, una muy rica vía de acceso al conocimiento, como se ha ocupado de resaltar Gerald Prince al señalar que el relato es un modo de enfrentarse al significado de los hechos, de percibir los efectos transformadores de una acción y de comprender el papel del tiempo en los asuntos humanos (Prince, 1987: 60). Y esto es posible, tal como apunta previamente, a que la narración no se limita a un simple recuento de cambios de estado, sino que también los hace posible y los intepreta, los idea y los explora.

La atención prestada al tratamiento temporal parece, entonces, obligada si consideramos que, en su caso, la intervención de un narrador supone también, e irremediablemente, una concreta ubicación en el tiempo. Nos referimos, por ejemplo, a si la información que aporta se corresponde con lo que un personaje conoce en un momento dado del transcurso de los acontecimientos o bien se trata de informaciones adquiridas a posteriori, lo cual, esto último, por otro lado, bien podría venir acompañado de un mayor grado de reflexividad.

Anotemos, a su vez, que, con la salvedad de El futuro, los citados filmes se unen a una tradición bien asentada en la historia del cine español: la predilección por aquellas propuestas fílmicas marcadas por la intervención de una voz o un personaje-narrador que necesariamente impregna la globalidad de la narración; que otorga, por tanto, un protagonismo esencial a los agentes que intervienen en la comunicación fílmica; que conforman, en definitiva, un discurso dotado de importantes dosis de reflexividad y autoconsciencia, de las cuales harán partícipe a un espectador que, de este modo, se siente directa y explícitamente implicado en los hechos narrados.

Sobre esto úlitmo, Carmina o revienta reclama ya desde un principio esta implicación del espectador a partir del recurso a un narrador homodiegético que, desde el interior del relato, asume esta función de hacer girar en torno a su figura cuanto se haga ver y saber. Primeramente, la interpelación directa al espectador mediante la mirada a cámara que desvela aquel fuera de campo con el cual establece comunicación y que hace consciente, por tanto, la presencia del espectador. Por su parte, El muerto y ser feliz construye un discurso plenamente constituido por lo que podemos considerar un narrador heterodiegético en voz over que, según lo expuesto más arriba, operando desde esa posición demiúrgica, somete 
la globalidad de la materia narrativa a su particular ver y saber a la vez que mantiene una actitud tutelar en relación con el destinatario del relato, lo que finalmente le conduce hacia un espacio de omnisciencia que, sin embargo, será también puesto en cuestión. En cuanto a El futuro, el régimen narrativo se adscribe, en principio, a un riguroso registro observacional. Sin voces externas que conduzcan el relato ni actante alguno que, desde el interior, focalice los hechos narrados, estos quedarían, por tanto, a cargo de un narrador extradiegético, un narrador impersonal ajeno a lo narrado, que solo recurre a códigos estrictamente cinematográficos que presentan las acciones desde el punto de vista más idóneo en cada momento. Pero se constata inmediatamente, no obstante, que la instancia enunciadora no actúa desde un espacio ajeno al universo diegético, sino que finge moverse en el interior del mismo, construyendo así la simulación de un personaje más que participa de la acción (recordemos: una fiesta en un piso particular), que se mueve por los espacios propios de la misma y que capta, y nos hace llegar, registros visuales y sonoros captados de un modo aparentemente indeliberado. Un personaje más, decimos, y, no obstante, desconocido o inexistente para los personajes sí visualizados, a los que se acerca casi hasta los límites de lo íntimo sin que éstos comuniquen de ningún modo haber advertido su presencia. Ajeno a la acción para quienes efectivamente - efectivamente porque los vemos y los oímos y somos conscientes de su existencia- participan de ésta, se integran en ella para quienes ocupamos ese fuera de campo heterogéneo donde se situa la mirada espectatorial.

\section{CARMINA O REVIENTA: LA CONSTRUCCIÓN NARRATI- VA RETROSPECTIVA}

Atendiendo al hábito del espectador, Carmina o revienta se presenta, de entrada, con una cierta apariencia documental, como así parecen simularlo, en primer lugar, ciertos estilemas derivados de la estrategia enunciativa. A dicho dominio de la no ficción correspondería, de un modo indudable, esa mirada a cámara que, inevitablemente, conlleva la interpelación directa al espacio de la recepción; un gesto fílmico que es además el gesto iniciador de todo el desarrollo narrativo en tanto que con él se procede a la presentación de los personajes principales, se informa de su condición, del rol que desempeñarán en el conjunto del relato y de los objetivos que perseguirán con sus acciones. Sobre esto último, cabe 
destacar que el relato se orienta desde un primer momento, y sin apenas explorar otras vías posibles, a la consecución de un objetivo muy claro, que no es otro que la puesta en práctica por parte de la protagonista, Carmina, de la estratagema urdida para cobrar el seguro del bar y poder así resarcirse de los sucesivos robos sufridos. La organización temporal y, por supuesto, el procedimiento enunciativo se ponen por completo al servicio de esta causa. Expongamos mínimamente cuáles son esa organización y ese procedimiento.

La articulación temporal del relato fija un momento de la enunciación, ocupado en exclusiva por la figura de Carmina, quien toma a su cargo la función propia de un narrador homodiegético, que narra los hechos, y que también protagoniza, desde el interior de la trama; figura sobre la cual gravitan los acontecimientos de aquel pasado inmediato que han conducido la situación hasta este momento nuclear; y del cual emerge la resolución de la trama, que será el único segmento fílmico situado en una posición futura respecto de aquel. "A ver como sale todo", afirma Carmina, quien, tras haber preparado su ardid, irá dando paso, uno tras otro, a varios flashback que van construyendo el discurso narrativo en la dirección que conduce hacia el momento culminante. En cada uno de estos segmentos fílmicos en los que se hace avanzar la acción hacia lo que hemos llamado el momento nuclear, aquel narrador explícito o bien abandona el acto de narrar para dar paso a las imágenes de su relato, o bien mantiene su narración oral, en lo que Chatman ha denominado escena retrospectiva parcial o dividida, es decir, aquella en la que uno de los canales de información se mantiene en el presente (en este caso, el auditivo) y el otro es retrospectivo (en este caso, el visual) (Chatman, 1990: 67). Esta es, por tanto, la particular articulación del programa narrativo de Carmina o revienta, dispuesto en torno al eje representado por la protagonista que da título al filme, quien adopta el rol de personaje-narrador, focaliza una buena parte del relato en lo que podríamos encuadrar en una focalización interna fija, según la terminología de Genette, retomada por Gaudreault y Jost (1995: 139) y que, conviene insistir en ello, demuestra un conocimiento pleno del universo de la ficción que aquí se despliega. El hacerse cargo de lo que la imagen muestra nos conduce, además, en determinados pasajes del filme, a la irrupción de la llamada ocularización interna primaria, la cual, tal como la han explicado Gaudreault y Jost (1995: 142) y, primeramente, el propio Jost (1987: 127) puede presentarse como un desplazamiento de 
la cámara acompañado de un cierto temblor o brusquedad de la imagen que remitiera al movimiento de un cuerpo y designara, de este modo, su posición respecto de lo mostrado. Así ocurre en la secuencia en la que se narra cómo Carmina y su hija recuperan el coche robado, concretamente en el momento en que la la madre sale del taxi y echa a correr hacia los ladrones.

De noche, mientras aguarda la llamada que le anuncie el nuevo robo en la venta para poder así dar curso final al plan previsto, Carmina adopta el ya tratado papel de agente narrador que, cual si formara parte de un reportaje informativo, habla a la cámara en un estricto plano frontal, relata la historia de su pasado y reflexiona en voz alta sobre los hechos que la han conducido hasta este momento. Con esta explícita introducción que recurre a una narración en primera persona, el relato se pone en marcha a partir de un momento de reflexión, paradójicamente, de calma y, principalmente, de espera: sabemos que esperamos que algo suceda pero no sabemos el qué, como el propio personaje-narrador aguarda que ocurra lo que tiene que ocurrir, que se cumpla el plazo que ha previsto para que fructifique el plan preparado de antemano. Frente a la inexorable marcha de los hechos, también hay, entonces, un momento de necesaria pausa, ese momento de espera, en la noche, en la cocina familiar, un tiempo muerto que aquí se aprovecha para que la protagonista-narradora haga explícito su papel y busque la complicidad del espectador a través del relato verbal de su pasado y de la explicación de su momento actual. Y de este modo, entre la espera de lo que ha de de ocurrir, como desenlace del conflicto aquí planteado, y el recuerdo del pasado inmediato, en el que se generó dicho conflicto, el relato se remansa en este preciso momento que, además de ser el punto de partida del discurso fílmico, acoge el núcleo generador de la trama. Este particular tratamiento discursivo permite crear una nítida consciencia del tiempo, que no por aparentemente detenido deja de estar sometido a su fluir constante; un tiempo que aquí alcanza toda su densidad en tanto que, anclado al relato de Carmina, se extiende hacia el pasado y hacia lo porvenir. Precisamente, al hablar del tiempo humano que se va haciendo en la medida en que se articula de un modo narrativo, como ya hemos adelantado, Paul Ricoeur explica este fenómeno de un devenir que fluye en las dos direcciones posibles: "En el momento en que el tiempo pasa, puede ser percibido y medido [...]. Lo que medimos es sin duda el futuro, entendido más tarde como espera, y el pasado entendido como 
memoria" (1988: 50).

Esa conexión que ya se establece aquí con el espacio de la recepción, tanto a través de la rotunda mirada frontal de la protagonista como del propio relato en primera persona, tendrá una profunda repercusión en la experiencia del espectador, como ha destacado Sara Kosloff, quien llama la atención sobre la identificación que esto propicia con los personajes, a la vez que aumenta la individualización y subjetivización de la percepción (1988: 41). Un mecanismo similar de identificación figura en la segunda película surgida alrededor de este mismo personaje, Carmina y amén (Paco León, 2014), si bien con el importante matiz de que se incorpora la figura de un narratario que, en el personaje del marido muerto, Antonio, se constituye en el interlocutor mudo de Carmina, siendo así destinatario de parte del relato desde el interior de la ficción. Se trata, de este modo, de un singular ejemplo de narratario representado, siguiendo la categorización propuesta por Josep Prosper (2015: 468). La propia Kosloff se ha referido de un modo bien revelador a esta poderosa identificación cuando señala que, a veces, la voz narradora (y también la voz over en su caso) está tan inscrita en el filme que parece que fue generada no únicamente por lo que ella ve, sino por lo que nosotros estamos viendo (1988: 45).

En la específica jerarquía enunciativa que ordena el texto fílmico reside, por tanto, la construcción del punto de vista en tanto que reúne la dimensión perceptiva, la cognitiva y la ideológica. La picaresca, la audacia e, incluso, la temeridad que guían las acciones de la protagonista responderían entonces a una determinada cosmovisión, a una forma de entender las cosas y de afrontar los problemas que son las que se imponen en la marcha de los acontecimientos. Al final, todo el desarrollo de los hechos responde a la forma de hacer las cosas de Carmina, tanto en lo que tiene que ver con el asunto principal (cómo lograr el dinero del seguro) como a la manera de solventar las dificultades que van saliendo al paso (el accidente de coche de la hija sin carnet, la visita del cobrador del frac,...) En un plano inferior, y puesto que hablamos de jerarquía, habrá que reservar un determinado espacio para los otros personajes que también asumen su parte alícuota de agentes narradores: la hija, María; el asistente, Braulio, y el marido, Antonio. Siendo, de este modo, narradores subsidiarios de aquel otro principal, el mecanismo focalizador que se articula en torno a su palabra y a su mirada a cámara abarca una parte pefectamente delimitada del territorio completo del relato. Únicamente son agentes de un mostrar, 
un narrar y un saber muy parciales. De igual modo, también en la ficción en la que se integran, sus acciones se limitan a seguir el camino marcado por la protagonista, tal como ocurre con el personaje de María. Se trataría, en todo caso, de una focalización múltiple, pues se ofrecen diferentes perspectivas de la situación general en la que se enmarca el relato, sin bien, insistimos, no en un nivel de igualdad. Todos ellos se adentran, por otro lado, en ese incierto territorio donde la ficción se niega a sí misma, o bien, si preferirmos referirnos a ello en otros términos, toma consciencia de su carácter artificioso, de su estatuto de representación, para adoptar aquella otra forma que, como hemos dicho, el hábito lector lo viene relacionando con el modelo documental.

En conclusión, si, efectivamente, el relato es un modo de percibir los efectos transformadores de una acción, en Carmina o revienta el flujo de la narración se conduce inexorablemente hacia el cumplimiento de un propósito, un objetivo hacia el que todo se hace derivar. Y es aquí donde interviene precisamente el particular régimen focalizador que adopta el sujeto narrador, pues, en la gestión de los saberes, se escamoteará al espectador la verdadera naturaleza de lo planeado, prácticamente hasta que éste se ha cumplido, sin nada más que pequeños indicios que puedan levantar algún tipo de sospecha, como es el caso de hechos tales como el de ver a Carmina serrando los barrotes de hierro de la ventana.

\section{EL MUERTO Y SER FELIZ: LA NARRACIÓN PRECARIA}

Al contrario que en Carmina o revienta, que se narra desde dentro y se deja conducir por un narrador homodiegético que domina cuanto ocurre, El muerto y ser feliz se observa y se comenta desde fuera, a cargo de un narrador heterodiegético en voz over, pero cuyo poder y (supuesto) dominio sobre el ver y sobre el saber se muestran erosionado por las reiteradas vacilaciones, dobles sentidos y falsedades. Y todo ello pese a la aparente firmeza de sus afirmaciones, como si cuanto más rotunda, sobria y eficaz se esfuerce por presentarse, mayor inseguridad acabe transmitiendo dadas las reiteradas contradicciones que se van sucediendo entre lo contado y lo mostrado.

Al capítulo de las expectativas frustradas que incluiría lo explicado sobre la voz narradora hay que incorporar, asimismo, lo relativo al desarrollo narrativo entendido como movimiento, cambio o transformación. A 
diferencia de Carmina o revienta, que sigue un plan plenamente preparado por quien asume el rol de narrador, en este otro filme, a pesar de dejar claro que el protagonista emprende una huida y que ésta es la principal motivación del viaje que se dispone a realizar, luego dicho viaje no manifiesta apuntar hacia ningún destino concreto. Como en el caso de la voz over, segura en las formas y vacilante en los contenidos, tambíen aquí se da a entender que hay un plan claro de actuación que luego no resulta tal. Los hechos narrados se acogen a un desarrollo en el tiempo que los impulsa en una determinada dirección, solo que no será posible saber en ningún momento cuál es exactamente esa dirección. Y tratándose de lo que, ya comúnmente, se conoce como una road movie, más fácil sería marcar aquella dirección, establecer desde un principio una meta, la ruta a seguir, incluso echando mano de la capacidad metafórica que bien podría hacerse emerger del concepto de ruta. El viaje en tanto que evidenciara el devenir del relato tampoco sirve, de este modo, como plan narrativo que proponer al espectador. Lo incierto del destino se explicita finalmente en estas bien reveladoras palabras de la voz narradora: "En Argentina ni todas las rutas están en los mapas ni existen todos los caminos que los mapas dicen. Pero Santos y Erika ni llevan mapas ni los precisan".

Si el relato experimenta un cierto desarrollo, una progresión que vaya más allá del deambular errático de la pareja protagonista, ello se manifiesta en el paulatino empeoramiento de la salud de Santos. Aquí sí es posible determinar un destino posible para el relato, que finalmente también se frustrará. Ya desde un principio el espectador recibe la información de que el punto último adonde se dirige el protagonista solo puede ser la muerte, o al menos los pasos que dé a partir de ese momento estarán marcadamente señalados por la amenaza de la muerte.

La incertidumbre sobre el destino de los personajes se corresponde con la frágil autoridad de la voz narradora. Como ya se ha indicado, bajo la apariencia de una estricta objetividad que denota un tono de firmeza y seguridad, las voces femenina y masculina que se van alternando solo pueden ofrecer un saber escaso, precario y manifiestamente reiterativo respecto de las acciones que el relato ya muestra. Respecto de esto último, la reiteración se anuncia desde un primer momento como otro de los principios ordenadores del comportamiento de la voz narradora, que en su primera comparecencia afirma lo que sigue: "Media mañana en esta gran plaza del centro de Buenos Aires que tiene el ambiente de una gran plaza 
del centro de Buenos Aires a media mañana".

En cuanto a aquella precariedad, se combate así el principio de que la voz over narradora se arroga la cualidad de omnisciente que le vendría dada por el lugar que ocupa, ese ámbito apartado de la diégesis, en una posición de dominio que le permitiría saberlo todo de los hechos y los personajes. Y ciertamente, el gran plano general de inicio que, descendiendo desde un ángulo cenital, se va cerrando sobre una plaza de la ciudad de Buenos Aires hasta detenerse sobre un banco y sobre el personaje que lo ocupa, afirma de entrada que esa voz que presenta los hechos y sitúa la acción posee todas las claves de la diégesis y, en consecuencia, no puede equivocarse. Pero las contradicciones, los errores y las afirmaciones del tipo "Esta es una de las pocas cosas que sabemos de Santos", echarán por tierra aquella supuesta omnisciencia. Desde la tradición del documental canónico y del noticiario, que habían educado en el hábito de este narrador invisible, como lo denominó Sarah Kosloff, se viene hablando de voz demiúrgica e incluso de la voz de Dios, es decir, aquella cuyo saber y dominio no se ponen en cuestión. En el marco de esta ficción titulada El muerto y ser feliz, sin embargo, se rompe ese contrato por el cual el espectador asume como cierto cuanto le es comunicado, por ejemplo cuando la voz señala que a aquella hora la piscina está ocupada por niños mientras vemos que son ancianos los que se bañan. Esta quiebra de la verdad implica, en consecuencia, el ingreso irreversible en un ámbito de duda e incertidumbre que, desde el momento en que la mentira es advertida, hace decaer aquel principio básico enunciado por Joseph Courtés en los siguientes términos: "El contenido de un enunciado solo es interpretable en relación con el juego que es establece entre el enunciador y el enunciatario" (1997: 62). Las reiteradas imprecisiones modifican, en todo caso, las reglas de este juego o más bien proponen otras, ciertamente poco habituales, las de la sospecha sobre cuanto enuncia la voz narradora, la cual, aun reiterando lo que ya la imagen evidencia no por ello se libra de incidir en el error, de tal modo que aquella afirmación de Courtés mantiene, entonces, su validez.

La frágil autoridad de esta voz narradora y la ausencia de certezas que conlleva se hacen notar desde un primer momento, como cuando afirma que la bolsa que entrega la enfermera a Santos está llena de frasquitos de morfina, pero, añade, "esto no podemos saberlo" y, por el contrario, a continuación sí parece tener un conocimiento mayor, capaz de adentrarse hasta lo más íntimo del personaje: "Santos dice que no, pero miente". E 
igualmente, más adelante, también manifiesta el mismo dominio sobre el personaje y su conciencia al asegurar que Santos no puede acordarse del nombre del primer hombre al que mató, si bien la confusión regresa cuando se asegura que Santos es un asesino que no asesina. La mentira y el disimulo son también habituales. Del protagonista se dice que ha tenido que mentir mucho y, siendo español, intentará imitar el acento argentino tratando de evitar una multa de tráfico, aunque la voz narradora asegura que en realidad no quiere imitar dicho acento y, además, "le sale bastante mal la tomada". Simula así estar en conocimiento de las verdaderas intenciones del personaje a la vez que realiza juicios de valor, de modo que, por esta vez, abandona aquella fría y sobria narración. Para más confusión, se invoca a otros comunicantes, comparecen sobre el entramado del discurso otros agentes que van a participar del dispositivo enunciador. Y así: "En el pueblo de San Lorenzo dicen que se encaprichó de un poncho", "Lo que pasó en el hotel de Tucumán solo Erika y unos cuantos han podido contarlo".

En relación con la citada quiebra de las expectativas, bien podría deducirse que estamos ante apelaciones a un espectador que deberá elaborar, y luego resolver, sus propias conjeturas, completar lo que falta y participar, en definitiva, en la completa configuración del relato. Las flagrantes contradicciones entre dos instancias de la enunciación, el narrador heterodiegético en voz over y el narrador extradiegético (impersonal y externo, que se manifiesta a través del amplio registro de codígos cinemáticos, como hemos recordado), abocan a decidir entre lo visto y lo oído (y aquello que vemos siempre prevalece sobre lo que oímos o lo que nos cuentan). Resulta llamativo, en definitiva, de qué modo ejerce aquí su control la instancia narradora. Según Genette, quien a su vez retoma las célebres funciones del lenguaje de Jackobson, el narrador puede referirse al texto narrativo de un modo metalingüístico para señalar sus articulaciones o su organización interna (Genette, 1989: 309). Y será precisamente en los momentos iniciales del relato donde la instancia narradora comience a dejar patentes sus limitaciones en la forma en la que pone en relación lo percibido y lo sabido: "Si pudiéramos verle más de cerca con más detenimiento"; "Santos hace un gesto que no sabemos si no sabe o que no quiere decirlo". Tengamos en cuenta, para hacer notar lo excepcional del caso, que, tratándose de un narrador que no se identifica con ningún personaje que participe en los hechos, su información resulta 
habitualmente fiable, pues responde así a un registro más del llamado meganarrador, tal como recuerdan quienes han abordado estos principios de la narratología en su aplicación al relato cinematográfico (Cuevas, 2007: 328). Si la consabida omnisciencia no llega a manifestarse como cabría esperar se aboca al espectador a una desorientación tal que convierte el texto fílmico en una suerte de campo minado por el que, no sin cierta fruición, habrá de transitar con igual errático deambular que los propios protagonistas, sabiendo además (o tal vez no) que "Santos ha tenido que mentir mucho".

\section{EL FUTURO: OBSERVACIÓN, PROXIMIDAD, PRESENTE DETENIDO}

Carmina o revienta articula un relato retrospectivo que avanza hacial el momento donde se sitúa la instancia narradora para luego continuar hasta el desenlace de la trama. El muerto y ser feliz deviene en un viaje que, entre dudas e imprecisiones, no lleva finalmente a ningún lado en concreto. El futuro, por su parte, se agota en un presente eterno, una suerte de tiempo detenido en el que asistimos a una fiesta de los años ochenta, sin agente narrador alguno que, ni adoptando la figura de un personaje-narrador ni la de una voz over omnisciente, disponga una determinada focalización sobre lo mostrado o tutele el relato en una determinada dirección, y sin siquiera articular un devenir narrativo que permita al filme avanzar en alguna dirección conocida, previsible o anunciada de antemano. Sí podemos, no obstante, establecer unas pocas balizas temporales que ayuden a localizar el texto en cuestión en unas concretas coordenadas históricas, en un tiempo y en un lugar fácilmente identificables: la España inmediatamente posterior a la victoria socialista de 1982, es decir, en ese preciso momento al que podemos referirnos como post-transición. Asimismo, cabe advertir de la contundente potencialidad metafórica de determinados segmentos que contribuyen a crear una cierta armazón temporal sobre la que disponer el texto fílmico: la rueda de prensa de Alfonso Guerra para dar cuenta de los resultados electorales, la canción de la campaña electoral con el eslogan Hay que cambiar, la primera intervención de Felipe González tras haber ganado aquellas elecciones y en la que destacan sus apelaciones a la esperanza (todo esto sobre la pantalla en negro) o, simplemente, la presencia de motivos decorativos tan propios de la época, como la pared 
cubierta de azulejos con motivos florales. Mención aparte merece la serie de fotografías del álbum familiar, mostradas mientras suena la canción cuya letra advierte, irónicamente, del peligro nuclear: aquí emerge la España de los últimos años de Franco, la del turismo y el desarrollismo, con la imagen del desfile de la guardia mora que escolta al dictador, o la del niño junto a la piscina con el brazo en alto y una chica al lado que trata, divertida, de evitar semejante saludo.

Más allá de estas referencias a una cierta idea de tiempo, a una invocación del pasado o a una sutil alusión al futuro, si recurrimos, por nuestra parte, a otra metáfora, podría afirmarse que el filme se nos presenta como una vela que arde sin consumirse. Los bruscos cambios de plano a modo de fogonazos que hacen notar intencionadamente su presencia, y que acentúan por tanto el carácter de representación del dispositivo, abonarían la citada metáfora. Siguiendo la conocida concepción de Gaudreault, se quedaría en el registro de la mostración sin avanzar hacia la narración, u ofreciéndose ésta de un modo ciertamente limitado. A pesar de la promesa del título, no hay futuro, sino solo un presente indefinido en el que la fiesta que ocupa el cuerpo central del filme parece no acabar nunca, a no ser en esa supuesta mañana posterior, de ambiente gris y desangelado. Sin cambio ni transformación alguna, no habiéndose dado proceso alguno al que acompañar en su desarrollo (únicamente, la victoria electoral socialista seguida de una fiesta), asistimos a la negación del relato, incapaz de imponerse ante la ausencia de un movimiento que permita su puesta en marcha.

Sin la acción planeada en Carmina o revienta ni el viaje, o road movie, de El muerto y ser feliz, donde al menos hay una promesa de desenlace, en El futuro la dimensión temporal queda reducida a un presente que no avanza o, visto de otro modo, a un pasado que permaneciera atrapado, congelado, incapaz de abandonar el momento de su manifestarse, más allá de unos pocos planos finales de una ciudad a la luz del día y donde destaca un rótulo de Se Vende, como posible alusión a ese futuro que no era el previsto. Enlazando con lo avanzado en torno al predominio de aquel registro de la mostración, habría que aludir a la intervención de un megamostrador fílmico (que ahogaría la hipotética participación del meganarrador), que actúa fundamentalmente sobre los niveles de la puesta en escena y de la puesta en cuadro de la articulación fílmica. Así lo explica Gómez Tarín, quien señala que ambos niveles se sitúan en torno al eje 
paradigmático de dicha articulación, el cual es esencialmente mostrativo y que, como es sabido, recoge todo aquello que puede estar en lugar de otra cosa (sea un plano en lugar de otro o un movimiento de cámara, una angulación, etc.) (Gómez Tarín, 2011: 108). Pues bien, El futuro, en buena medida, dispone su contrucción discursiva sobre este mismo eje, allí donde lo que predomina es la posibilidade del intercambio de un elemento por otro, frente a la ordenación secuencial que impera en todo relato, que se organiza, también y fundamentalmente, sobre el eje sintagmático, el de la sucesión y el encadenamiento causal. La materia fílmica se nutre, entonces, de lo imprevisible, no en tanto que sorpresivo sino en relación con lo no ordenado o planificado, con lo indeterminado por no responder a un patrón de organización narrativa explícitamente expuesto; en definitiva, domina la idea de lo contingente por cuanto que lo que ocurre de un modo podía haber ocurrido de otro. Aquello que se muestra en un momento dado podía ser fácilmente sustituido por lo que sucede en otro instante. La contingencia puede, por tanto, explicarse aquí en los términos adoptados por Mary Ann Doane: una reserva de libertad y de juego, irreductible a la estructuración sistemática del tiempo (2012: 30). Y ciertamente, al modo, por ejemplo, de aquellos registros cinematográficos de lo amateur y de lo familiar, los del antiguo cine de Súper 8 (ocupados en fiestas y celebraciones, como en El futuro), también en este filme, si atendemos a lo planteado por la citada autora, la contingencia supone, finalmente, una fuente de asombro y de temor, de hechizo y de amenaza (Doane, 2012: 32). A ello abocaría esta ausencia de un devenir claramente marcado, de un plan de ruta narrativo que facilitara la creación de una expectativa espectatorial.

A falta de un relato en desarrollo, la instancia enunciadora adopta lo que hemos llamado megamostrador que, en el caso que nos ocupa, despliega una actitud eminentemente observacional, una suerte de behaviorismo fílmico. Sin adoptar, en consecuencia, el rol de un personaje-narrador, el punto de vista se sitúa, no obstante, en el interior de lo mostrado. Siguiendo lo establecido por Casetti, y expuesto más arriba, consideramos aquí punto de vista en su acepción perceptiva, en tanto que lugar físico de observación, pero también en la cognitiva, por cuanto que muestra ciertas cosas y oculta otras, selecciona aspectos de lo visible y proporciona determinadas informaciones, como así denota ese afán indagatorio, de proximidad y casi de instrusismo. Se muestra, entonces, desde dentro, como si se imitara la muy familiar cámara subjetiva por lo que ésta tiene de conexión con lo 
observado y de integración, ya que, como es sabido, empareja la mirada del personaje (supuesto personaje en el caso de este filme) con la del espectador. Pero, insistimos, hablamos aquí de un plano subjetivo simulado y no real. En ningún momento, además, su presencia resulta advertida, sugerida o denunciada por miradas que le fueran devueltas o por cualquier otro gesto interpelativo. La dominancia de primeros planos y la extrema proximidad, en ocasiones desde la distancia de lo íntimo, a los rostros, a la gestualidad y a los ademanes, nos habla de una mirada que procede con la minuciosidad del entomólogo, ocupada así en una observación atenta, interesada en explorar grupos, parejas e individuos concretos, como quien estudiara un comportamiento o se interrogara sobre sus actitudes y formas sociales de relación, lo cual, por otro lado y como es sabido, se logra a nivel técnico mediante el uso del teleobjetivo. Con las conversaciones que únicamente acceden a un primer plano sonoro de un modo fragmentado, pues se mantienen, en su mayor parte, como un murmullo ininteligible sobre la música diegética que las ahoga, todo se fía a una observación tan próxima en lo espacial como distante en lo afectivo.

\section{CONCLUSIONES}

El dispositivo enunciador que ordena los tres relatos que aquí hemos analizado van de la máxima identificación y dominio sobre lo narrado de Carmina o revienta a la observación fría y deshumanizada de El futuro. En medio, la voz narradora de El muerto y ser feliz finge una seguridad que no posee y rompe, de este modo, con el principio de omnisciencia que el espectador acostumbra atribuirle. Constituyen, por tanto, tres casos muy distintos de gestionar el ver y el saber, e incluso el creer o el suponer. Representan así muy diversas maneras de dosificar la información que ayude a la comprensión de las tramas, tres modelos de mostrar un mundo filtrado desde un determinado posicionamiento que, como sabemos para el caso de toda materia de expresión audiovisual, es un posicionamiento, a la vez, físico, cognitivo e ideológico, que es como decir perceptual y mental, y que es como debemos entender aquí el concepto de punto de vista. Se trata, en definitiva, de tres diferentes modelos de construcción narrativa en los que el agente narrador establece una relación con el interior y el exterior de la diégesis, según se sitúe en ella o ocupe un lugar en los márgenes. Y constituyen, a su vez, otras tantas maneras de inducir una determinada 
percepcion temporal: un presente que reconstruye el pasado inmediato y se mantiene a la espera de un desenlace en el futuro, una progresión en falso que se vehicula sobre un viaje sin destino y un presente que se agota en sí mismo y establece un contacto precario con elementos concretos del pasado y del futuro. Conviene insistir, a este respecto, en que el régimen narrativo no debe disociarse en cada caso de un particular tratamiento del devenir temporal.

Finalmente, es una cuestión de distancia, de implicación en lo narrado, en cómo esto repercute en el flujo del relato y, principalmente, en cómo se invita al espectador a participar en él. Hablemos de focalización, de filtrado o dosificación del saber narrativo, cabe concluir que buena parte de lo que aquí se dirime se refiere a una cuestión de grado en la amplitud de aquella implicación: de la interpelación directa de Carmina, con su alocución al fuera de campo heterogéneo que, en consecuencia, resulta atraído por esa mirada hacia el espacio de la recepción, hasta la observación atenta, próxima, indagadora, pero ajena al universo diegético de El futuro. En este sentido, cabe acogerse a las sabias palabras de Genette: "la ausencia también tiene sus grados y nada se parece más a una ligera ausencia que una presencia difusa" (1993: 73). Y a continuación se pregunta a qué distancia se empieza a estar ausente. Resulta significativo en este sentido llamar la atención sobre esta ambigua zona de las presencias / ausencias difusas en la que el concepto de distancia es aquí fundamental para medir aquel grado de subjetivismo por el cual se filtra lo mostrado y lo narrado. $\mathrm{Y}$ el propio Genette parece haberse quedado atrapado en esta dificultad para establecer una frontera clara entre ambas nociones, aparentemente contrarias, pues en una obra anterior había hecho una afirmación distinta a la expuesta anteriormente: "La ausencia es absoluta, pero la presencia tiene grados" (Genette, 1989: 299). En ese simulacro de una vida que parece pasar ante la cámara, como logran dar a ver (y a entender) los filmes de Paco León y de López Carrasco, se pone en juego aquella cuestión nodal de la distancia, acerca de la cual han asegurado Comolli y Sorrel en la entrada dedicada al cine directo (y algo de ello hay, ciertamente, en ambas películas) en su diccionario-ensayo: "Al cine le corresponde saber abolir las distancias y mantenerlas a la vez. La distancia justa, piedra de toque del gesto cineamatográfico" (2016: 100). 


\section{REFERENCIAS BIBLIOGRÁFICAS}

BAL, M. (1985). Teoría de la narrativa (Una introducción a la narratología). Madrid: Cátedra.

BORDWELL, D. (1996). La narración en el cine de ficción. Barcelona: Paidós.

CASETTI, F. (1989). El film y su espectador. Madrid: Cátedra. (2003). Cómo analizar un film. Barcelona: Paidós.

CHATMAN, S. (1990). Historia y discurso: la estructura narrativa en la novela y en el cine. Madrid: Altea.

COMOLLI, J. L. y SORREL, V. (2016). Cine, modo de empleo. De lo fotoquímico a lo digital. Buenos Aires: Manantial.

COURTÉS, J. (1997). Análisis semiótico del discurso. Del enunciado a la enunciación. Madrid: Gredos.

CUEVAS, E. (2007). "Las aportaciones de la narratología al análisis fílmico. Metodologías de análisis del film". En Actas del I Congreso Internacional sobre Análisis Fílmico, J. Marzal Felici y F. J. Gómez Tarín (coords.), 321-331. Madrid: Edipo.

DOANNE, M. A (2012). La emergencia del tiempo cinemático. La modernidad, la contingencia, el archivo. Murcia: CENDEAC.

GAUDREAULT, A. y JOST, F. (1995) El relato cinematográfico. Cine y narratología. Barcelona: Paidós.

GENETTE, G. (1989). Figuras III. Barcelona: Lumen.

(1993). Nuevo discurso del relato. Madrid: Cátedra.

GÓMEZ TARÍN, F. J. (2011). Elementos de narrativa audiovisual. Expresión y narración. Santander: Shangrilá.

JOST, F. (1987). L'Oeil - Caméra. Entre film et roman. Lyon: Presses Univesitaires de Lyon.

KOSLOFF, S. (1988). Invisible Storytellers. Voice-Over Narration in American Fiction Film. Los Angeles: Universtiy of California Press.

PRINCE, G. (1987). A Dictionary of Narratology. Lincoln: University of Nebraska Press.

PROSPER, J. (2015). "La presencia del narratario en el relato audiovisual". Signa. Revista de la Asociación Española de Semiótica 24, 463478. 
RICOEUR, P. (1988). Tiempo y narración. Configuración del tiempo en el relato histórico. Madrid: Editorial Cristiandad.

STAM, R.; BUORGOYNE, R. y FITTERMAN-LEWIS, S. (1999). Nuevos conceptos de teoría del cine. Estructuralismo, semiótica, narratología, psicoanálisis, interxtualidad. Barcelona: Paidós.

Recibido el 16 de mayo de 2017.

Aceptado el 16 de junio de 2017. 